\title{
Culture and characterisation of epithelial cells from human pterygia
}

Nick Di Girolamo, Nicodemus Tedla, Rakesh K Kumar, Peter McCluskey, Andrew Lloyd, Minas T Coroneo, Denis Wakefield

\begin{abstract}
Backgroundlaims-Pterygia are a common disorder of the ocular surface. The disease represents a chronic fibrovascular and degenerative process thought to originate at the conjunctival-corneal junction, where altered limbal stem cells are proposed to be the cell of origin. Extensive epidemiological evidence exists to implicate ultraviolet $B$ irradiation in the pathogenesis of pterygia. To date no animal or in vitro culture model has been developed to test such an hypothesis. The aim of this study was to establish and characterise a pure population of epithelial cells derived from pterygium tissue.
\end{abstract}

Methods-Tissue specimens were obtained from patients undergoing pterygium excision. Explants were cultured in either serum free or serum supplemented medium. Primary and passaged cells were processed for light microscopy, analysed by flow cytometry, and characterised immunohistochemically using specific antibodies.

Results-In serum free culture, cuboidal cells with typical morphology of epithelial cells migrated from the pterygium explants from 3 days onwards and eventually formed a cohesive monolayer. Passaged cells consisted of $\mathbf{9 8 . 4 \%}$ cytokeratin positive cells and demonstrated immunoreactivity for multiple cytokeratins, including AE1, AE3, AE5, but were negative for AE8. These cells also expressed an epithelial specific antigen, together with vimentin and mucin, as did epithelial cells in sections of pterygia.

Inflammation of Pathology, University of New

South Wales, Australia

N Di Girolamo

N Tedla

R K Kumar

P McCluskey

A Lloyd

D Wakefield

Department of

Ophthalmology, Prince

of Wales Hospital,

Sydney, 2052, Australia

$\mathrm{M} \mathrm{T}$ Coroneo

Correspondence to: Dr Nick Di Girolamo, Inflammation Research Unit, School of Pathology, The University of New South Wales, Sydney, 2052, Australia.

Accepted for publication 18 May 1999 type I hypersensitivity reactions, $T$ cell mediated type IV hypersensitivity responses, ${ }^{2}$ accelerated fibroblast proliferation, ${ }^{3}$ drying of cor- nea and conjunctiva, ${ }^{4}$ and the predominance of an angiogenesis factor. ${ }^{5}$ However, the most widely accepted explanation implicates ultraviolet irradiation as the major causative factor $^{6}$ and may well incorporate aspects of the other proposed mechanisms.

While some researchers consider this growth to be of conjunctival origin, ${ }^{7}$ others have suggested that the disease originates from altered limbal basal epithelial cells. ${ }^{89}$ We have postulated that the nasal predilection for this disease and its focal nature are the result of focusing of peripheral light by the anterior eye onto the limbus. ${ }^{10}$ This incident light is concentrated 20-fold onto the distal limbus, striking the basal epithelial cells from behind, resulting in a breakdown of the limbal barrier. ${ }^{10}$

Our model of pterygium formation ${ }^{11}$ explains the shape of these lesions in terms of focal limbal damage and the centripetal migration of limbal epithelial cells, which may be analogous to the behaviour of these cells in the healing of corneal wounds. ${ }^{12}$ Although primary culture of human conjunctival, ${ }^{13}$ corneal, ${ }^{14}$ and limbal ${ }^{15}$ epithelium has been described, culture and characterisation of epithelial cells derived from pterygia has not previously been reported. The present study describes a simple technique of establishing long term cultures of epithelial cells derived from human pterygia. This in vitro culture system may help to elucidate mechanisms of pterygium formation.

\section{Materials and methods}

TISSUE CULTURE

Pterygium specimens were obtained from patients undergoing routine pterygectomy at Greenoaks Hospital, Sydney, Australia. Informed consent was obtained from each patient. Fresh tissue was used immediately after surgery for culture $(n=4)$, while other specimens $(n=20)$ were fixed in $10 \%$ buffered formalin or Carnoy's solution for histochemical analyses.

Fresh pterygium specimens were placed in six well culture plates (Nunc, Roskilde, Denmark) containing $500 \mu \mathrm{l}$ phosphate buffered saline (PBS). Sterile technique was used to dissect away surrounding normal corneal and conjunctival tissue, and the pterygium was subsequently cut into several $1-2 \mathrm{~mm}^{2}$ pieces and placed into a new well. Explants were allowed to attach to the substratum for at least 8 hours before adding media. Explants were either cultured on surfaces coated with collagen (rat tail collagen type I, Sigma, Australia) in serum free medium ${ }^{16}$ at $37^{\circ} \mathrm{C}$ in an atmosphere of $2 \%$ carbon dioxide in air; or on uncoated tissue culture plastic in Eagle's MEM 
Table 1 Monoclonal antibodies used to characterise PEC

\begin{tabular}{lllll}
\hline MoAbs & Source & DF & IR & Specificity \\
\hline AE1 & ICN & $1: 50$ & + & Acidic keratins (type I) \\
AE3 & ICN & $1: 50$ & + & Basic keratins (type II) \\
AE5 & ICN & $1: 50$ & + & 64 kDa keratin (corneal type differentiation) \\
AE8 & ICN & $1: 50$ & - & $51 \mathrm{kDa}$ keratin (non-keratinising epithelium) \\
AE1/AE3 & Dako & $1: 50$ & + & Pan-cytokeratin (acidic and basic keratins) \\
MUC-1 & Serotec & $1: 50$ & + & Mucin \\
ESA & Zymed & $1: 50$ & + & $40 \mathrm{kDa}$ epithelial antigen \\
VM & Dako & $1: 20$ & + & $57 \mathrm{kDa}$ intermediate filament protein \\
CD1 & Dako & $1: 50$ & - & Langerhans cells \\
CD68 & Dako & $1: 50$ & - & Macrophages \\
vWF & Dako & $1: 50$ & - & Endothelial cells \\
Mouse IgG $_{1}$ & Dako & $1: 50$ & - & Non-specific \\
$\mathrm{C}^{1} 11^{\mathrm{FTC}}$ & Sigma & $1: 20$ & + & Pan-cytokeratin (acidic and basic keratins) \\
$\mathrm{IgG}_{1}{ }^{\mathrm{FTC}} / \mathrm{IgG}_{2 a}{ }^{\mathrm{PE}}$ & BD & $1: 20$ & - & Not specific
\end{tabular}

$\overline{\mathrm{BD}}=$ Becton Dickinson; $\mathrm{DF}=$ dilution factor; ESA = epithelial specific antigen; IR = immunoreactivity; $\mathrm{MoAbs}=$ monoclonal antibodies; $\mathrm{VM}=$ vimentin; $\mathrm{vWF}=$ von Willebrand factor; $(+)$ positive and $(-)$ negative specific immunoreactivity in cultured PEC. Becton Dickinson, Dako, ICN, and Sigma (Sydney, Australia); Zymed, (San Francisco, CA, USA); Serotec, (Oxford, UK).

(Trace Biosciences, Sydney, Australia) supplemented with $10 \%$ fetal bovine serum (FBS; Trace Biosciences) and $100 \mathrm{U} / \mathrm{ml}$ penicillin, $100 \mu \mathrm{g} / \mathrm{ml}$ streptomycin and $2.5 \mu \mathrm{g} / \mathrm{ml}$ fungizone (Trace Biosciences) at $37^{\circ} \mathrm{C}$ in an atmosphere of $5 \%$ carbon dioxide in air. Cell migration from explants was observed within 3-5 days in both media. Cells cultured in serum free media were detached by $3-5$ cycles of incubation at $37^{\circ} \mathrm{C}$ for 60 seconds with $0.025 \%$ trypsin (Trace Biosciences) until weeks 3-4. Primary cultures were grown for not more than 3-4 weeks owing to the increasing presence of spindle-shaped cells. Cells were passaged at weekly intervals thereafter and used at passage 4,10 , and 25 for characterisation studies.

For histochemical studies, cells were cultured in 16 chamber slides (Nunc) and fixed in $100 \%$ methanol for 5 minutes. Populations of cells were expanded in $165 \mathrm{~cm}^{2}$ flasks (Nunc), trypsinised, pelleted, fixed in $10 \%$ formalin or Carnoy's solution, embedded in paraffin, and sectioned for immunohistochemical analyses.

IMMUNOHISTOCHEMICAL ANALYSIS

Cell pellet sections of cultured pterygium cells as well as sections of pterygium tissue were cut $4 \mu \mathrm{m}$ thick and mounted on glass slides. Deparaffinised sections were immunostained as previously described. ${ }^{17}$ Endogenous peroxidase was inhibited and non-specific binding was blocked with a 1:5 dilution of pre-immune goat serum for 30 minutes. Mouse MoAbs (see Table 1) were applied for 30 minutes, and a 1:200 dilution of biotinylated goat anti-mouse immunoglobulins (Dako Corp, Sydney, Australia) was applied for 30 minutes. Streptavidin conjugated HRP was added for 1 hour and each section was treated with 3-amino-9ethylcarbazole (AEC) (Sigma, Sydney, Australia). Cells were counterstained with haematoxylin and viewed by light microscopy.

FLOW CYTOMETRIC ANALYSIS

Flow cytometric analysis was performed on subcultured cells at passage 10 according to a standard direct immunofluorescence tech-
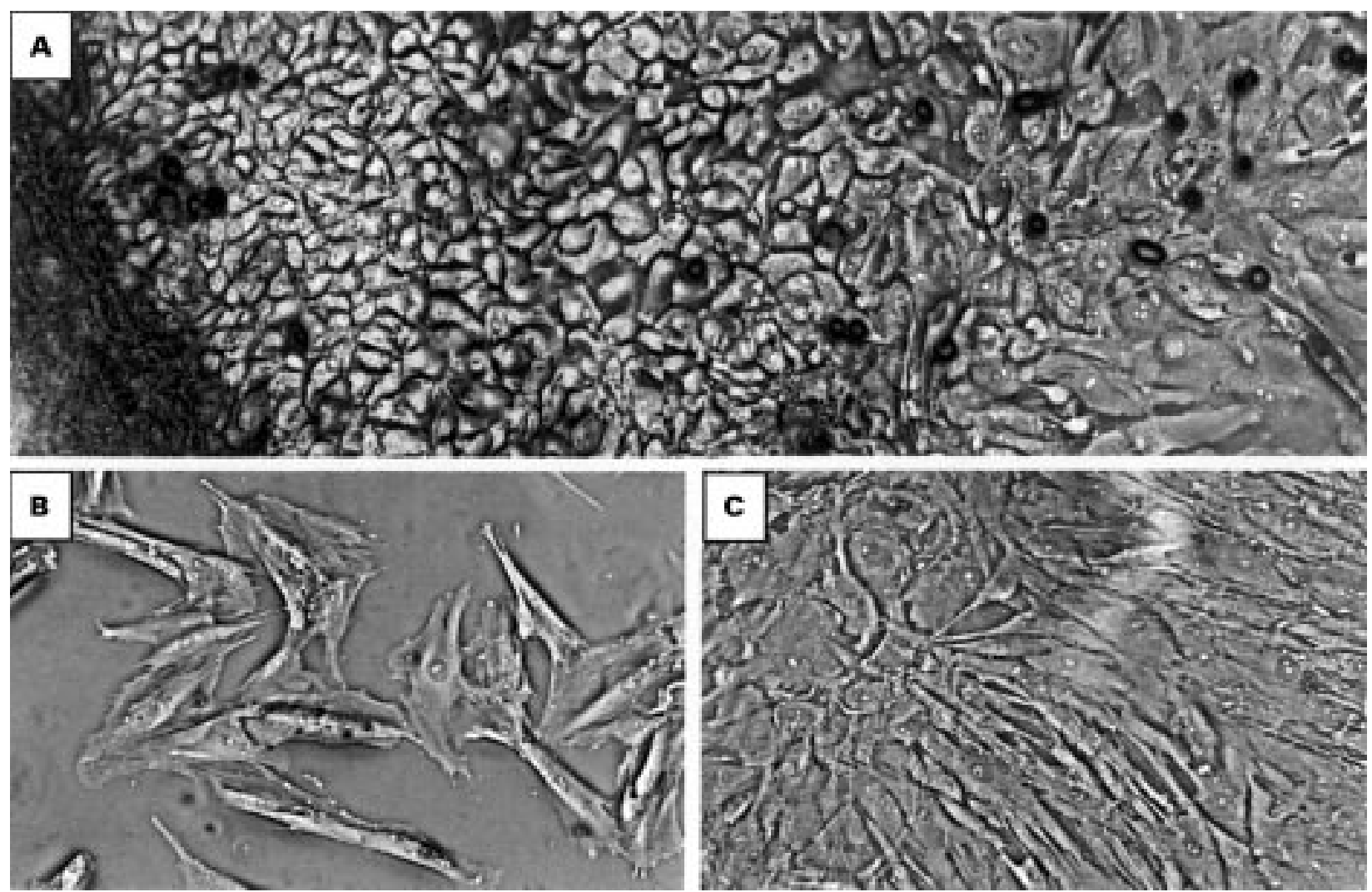

Figure 1 Phase contrast microscopy of primary and passaged human pterygium derived cells. (A) Primary explant culture of pterygium tissue (dark region, left on micrograph), grown in serum free media on collagen coated tissue culture plastic. Cell outgrowth was extensive, with cells displaying cuboidal morphology typical of epithelial cells. (B) Passaged cells were subcultured on uncoated surfaces in the presence of serum. Note the flattened morphology, similar to the cells observed at the leading growing edge in primary culture. (C) Confluent cells (cultured as in (B)) appear morphologically similar, suggesting a homogeneous population of cells. Cells in (B) and (C) were derived from passage 10 cultures and similar morphology was observed at earlier and later passages. All micrographs were taken at an original magnification of $\times 100$. 
nique. ${ }^{18}$ Briefly, after trypsin digestion, cells were allowed to re-establish protein expression for $1-2$ hours at $37^{\circ} \mathrm{C}$ in washing buffer $(2 \%$ FBS/PBS). The cells were counted, centrifuged at $400 \mathrm{~g}$ for 5 minutes, washed in PBS, resuspended in cold $100 \%$ methanol, and permeabilised for 10 minutes at $-20^{\circ} \mathrm{C}$. Cells were centrifuged to remove the methanol, resuspended in cold $0.1 \%$ Triton X-100 (Sigma), immediately centrifuged at $400 \mathrm{~g}$ for 5 minutes, diluted in $300 \mu \mathrm{l}$ of PBS, and aliquoted into each of three tubes for direct immunofluorescence. Cells were incubated with FITC conjugated Abs (see Table 1) for 30 minutes, washed three times in $2 \% \mathrm{BSA} / \mathrm{PBS}$, and resuspended in $1 \%$ paraformaldehyde. Data were acquired with a FACS Calibur flow cytometer (Becton Dickinson, San Jose, CA, USA) and processed with the Cell Quest software program (Becton Dickinson).

\section{Results}

PRIMARY AND SUBCULTURE OF PTERYGIUM

DERIVED CELLS

Cell outgrowth from explants was observed within 3-5 days in both serum free (Fig 1A) and serum supplemented media (data not shown). Phase contrast microscopy revealed that primary outgrowths of cells cultured in serum free medium exhibited morphology typical of epithelial cells (Fig 1A). Primary cultures in serum free medium grew significantly slower than cells from explants cultured in the presence of $10 \%$ FBS. Although similar cellular morphology was observed in serum supplemented medium, the propagation of epithelial cells free of other contaminating cells was less efficient. After 3-4 weeks in primary culture, cells were trypsinised and seeded on uncoated tissue culture plastic in 10\% FBS. These subcultured cells grew rapidly and were subsequently passaged once weekly. Cells cultured in the presence of serum appeared more irregular and grew in less well organised monolayers (Fig 1B and C).

\section{CHARACTERISATION OF PTERYGIUM DERIVED}

EPITHELIAL CELLS

Cultured cells and cell pellets sections were examined for cytokeratin expression. Immunostaining results are summarised in Table 1 . Cells incubated with the MoAbs AE1 (Fig 2A),
AE5 (Fig 2B), and AE3 (Fig 2C) all demonstrated intense cytoplasmic immunoreactivity for these keratins. However, no immunoreactivity was demonstrable when cells were incubated with the AE8 MoAb (a marker of non-keratinising epithelium) (Fig 2D). Intracellular keratin staining was generally filamentous (Fig 2B and C). Cultured cells also stained positively for the $40 \mathrm{kDa}$ epithelial cell specific antigen (ESA) (a glycoprotein found exclusively on the surface of epithelial cells) (Fig 2F). Similarly, cells displayed intense cytoplasmic staining for vimentin (Fig 2G). Cells incubated with no primary $\mathrm{Ab}$, with CD1, CD68, von Willebrand Factor (micrographs not shown), or with an isotype control MoAb (Fig 2E and inset (G)) demonstrated no reactivity. Thus the population of cultured cells appeared unlikely to be contaminated by Langerhans cells, macrophages, or endothelial cells and is hereafter referred to as pterygium epithelial cells (PEC). Identical staining patterns were observed with cells of earlier and latter passages (micrographs not shown).

PEC were also assessed for periodic acid Schiff (PAS) staining with or without diastase pretreatment for 1 hour at $37^{\circ} \mathrm{C}$. Diastase resistant, granular cytoplasmic staining with PAS was observed (Fig $2 \mathrm{H}$ ). Mucin production by these cells was confirmed by incubating cells with the MUC-1 MoAb (Fig 2I).

The purity of the cultured PEC was also evaluated by flow cytometry using an FITC conjugated pan-cytokeratin MoAb. In terms of size and granularity (forward and side scatter on the FACS), PEC appeared to be a homogeneous population of cells (Fig 3A). The flow cytometric immunofluorescence analyses indicated that at least $98 \%$ of the cell population consisted of cytokeratin positive epithelial cells (Fig 3C). Similar fluorescence was observed with cells of earlier and latter passage (data not shown).

\section{CHARACTERISATION OF EPITHELIAL CELLS IN} PTERYGIUM DERIVED TISSUE

In parallel studies, sections of pterygia were immunostained with the same MoAbs used to characterise PEC. The profile of cytokeratin expression is illustrated in Figure 4. Specific cytoplasmic reactivity for AE1 (Fig 4A), AE5 (Fig 4B), and AE3 (Fig 4C) was observed. Of
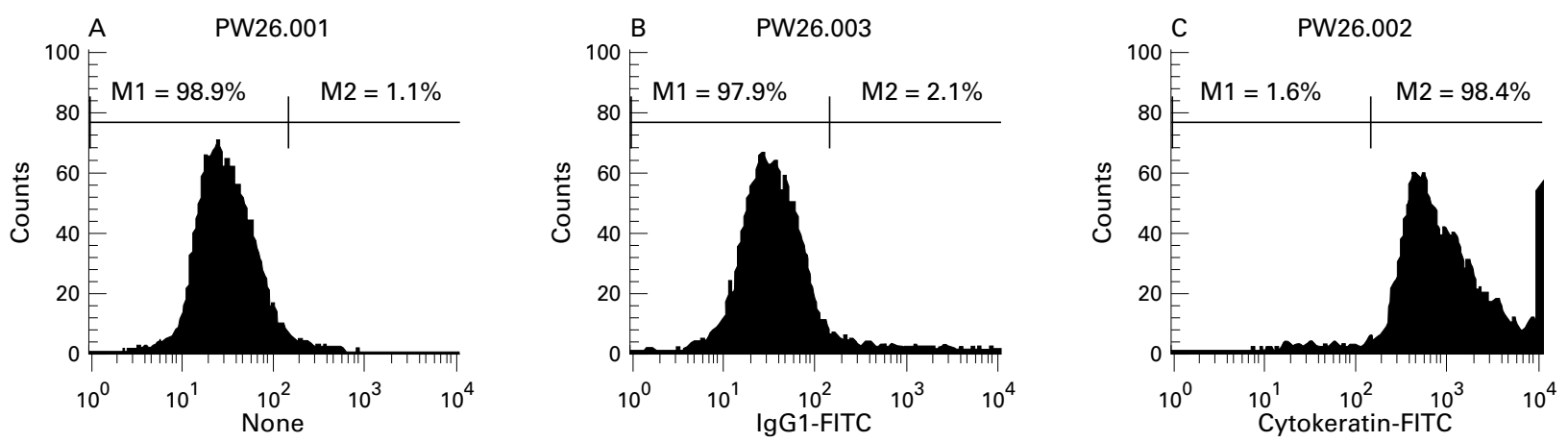

Figure 3 Flow cytometric analysis of cultured PEC. PEC at passage 10 were fluorescently labelled with a mouse anti-human pan-cytokeratin MoAb to determine the purity of cells in culture. The histograms generated indicate a homogeneous population of cultured cells $(A), 98.4 \%$ of which are cytokeratin expressing $(C)$. Minimal fluorescence was observed with a control $A b(B)$. Similar results were obtained on three other occasions using cells of earlier and later passages. 

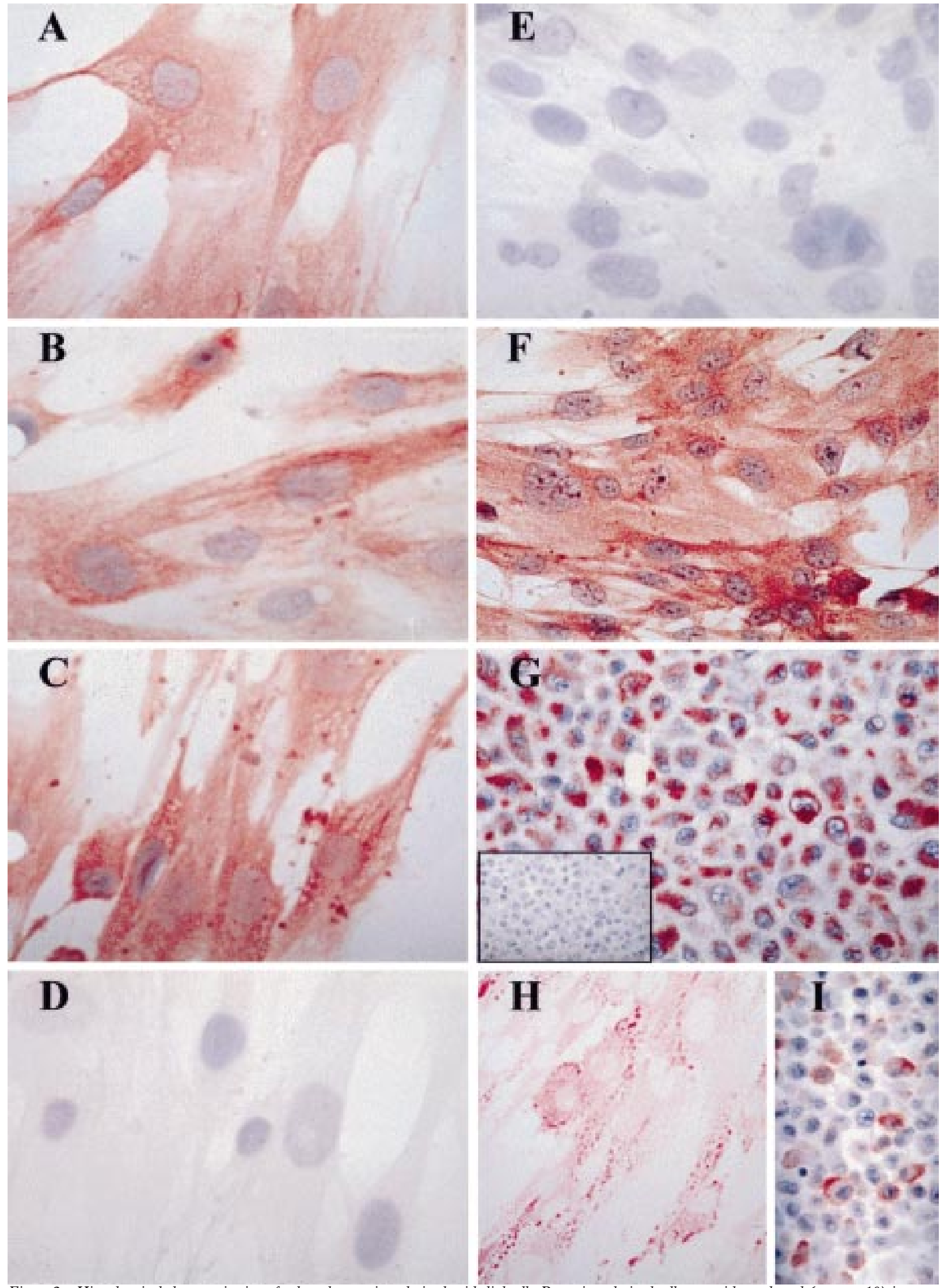

Figure 2 Histochemical characterisation of cultured pterygium derived epithelial cells. Pterygium derived cells were either cultured (passage 10) in chamber slides and fixed in methanol as mentioned in Materials and methods ( $A-F$, and $H$ ) or cell pellet sections cut $(G, I$, and inset $G$ ) and used for histochemical analyses. Positive immunoreactive signal is denoted by red staining derived from the AEC chromogen. In all panels (except $H$ ) the cells were counterstained with haematoxylin. Cells incubated with the AE1 (A), AE5 (B), and AE3 (C) MoAbs demonstrated strong and specific cytokeratin immunoreactivity. Note the filamentous staining pattern observed with some MoAbs (B and C). No reactivity was observed with the AE\& Ab (D) or with an isotype control MoAb (E and inset $G$ ). All cultured cells uniformly expressed ESA $(F)$, vimentin $(G)$, stained positively with PAS (H), and were reactive to the MUC-1 MoAb (I). This staining pattern is representative of three separate experiments. Original magnification $\times 500$. 

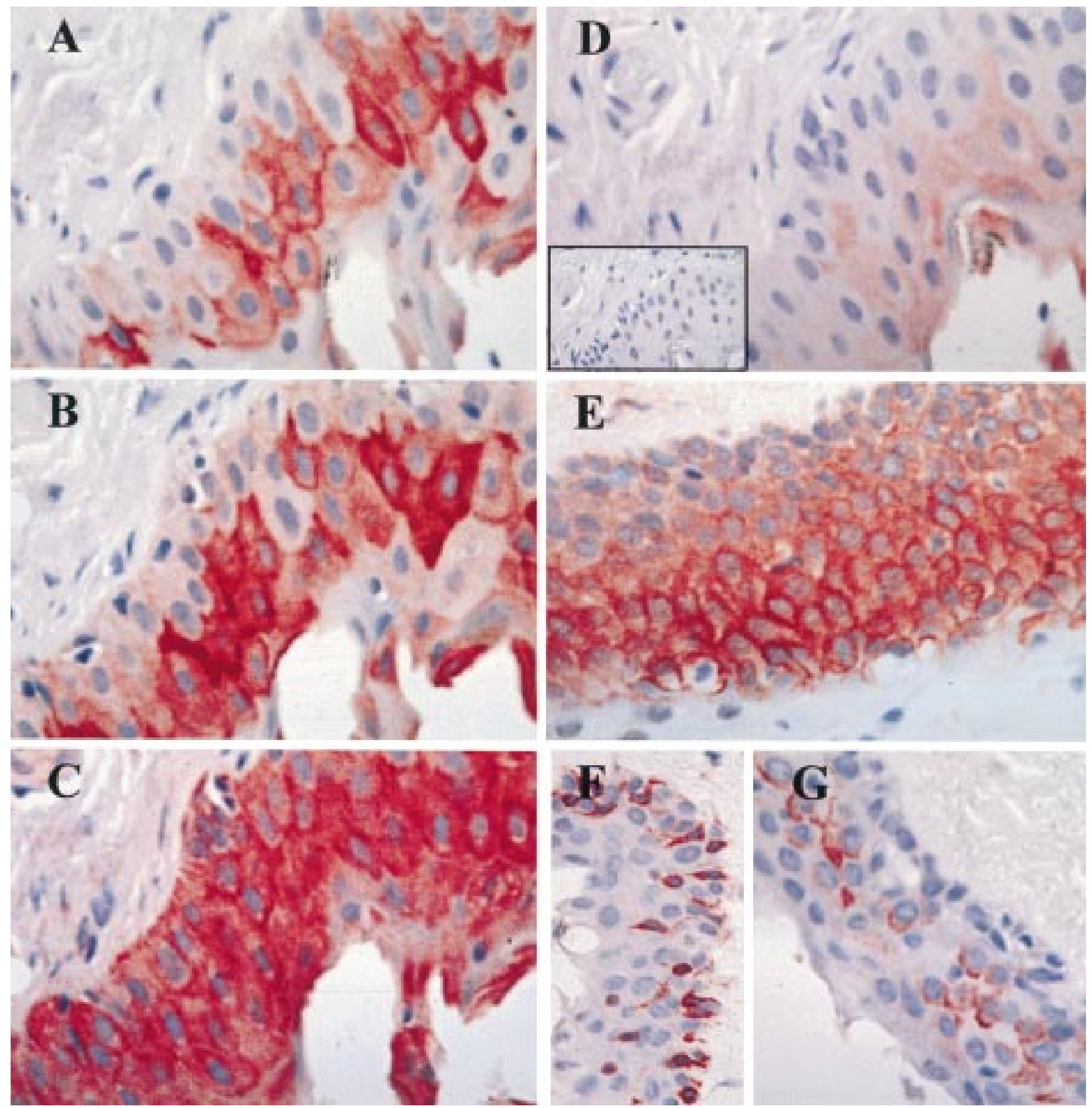

Figure 4 Immunohistochemical characterisation of epithelial cells in pterygia. Serial pterygium tissue sections $(A-D$ and inset $D)$ were incubated with the AE1 (A), AE5 (B), AE3 (C), AE8 (D) and an isotype control MoAb (inset D). Although the number of cells expressing the different keratins varied in the sections, some cells co-express AE1,AE3, and AE5. Very little or no reactivity was observed when tissue sections were stained with AE $8(D)$ or the isotype control MoAb (inset $D$ ). Abundant expression of $E S A(E)$, vimentin $(F)$, and mucin $(G)$ was also noted in pterygium tissue, predominantly in the epithelium. Tissue sections were stained and counterstained as in Figure 2. These results are representative of all pterygium tissue studied. Original magnification $\times 640$.

note was the differential staining pattern exhibited by these three MoAbs. The extent of reactivity was $\mathrm{AE} 3>\mathrm{AE} 5>\mathrm{AE} 1$. However, as demonstrated using serial sections (Fig 4A-C), numerous epithelial cells were identified with all three MoAbs. In contrast, little or no immunoreactivity was observed with AE8 (Fig 4D). Sections of pterygia were also stained for ESA. Intense cell membrane associated immunoreactivity for this antigen was observed, particularly prominent in the basal epithelial cell layers (Fig 4E). Vimentin expression was also apparent in basal epithelial cells (Fig 4F) and in resident connective tissue cells with typical fibroblast morphology (micrograph not shown). In addition, immunoreactivity for mucin was apparent in sections of diseased tissue incubated with the MUC-1 MoAb (Fig 4G). This pattern of immunoreactivity correlated in all respects with the staining of cultured PEC.

\section{Discussion}

The ocular surface is composed of three types of epithelia-conjunctival, corneal, and limbal, each differing in cellular composition. The conjunctival epithelium contains secretory cells-namely, goblet cells; the corneal epithelium is composed of a non-keratinising squamous epithelium; and the limbal epithe- 
lium, which is the transition zone between the conjunctival and corneal epithelium, contains limbal stem cells. ${ }^{19}$ The present study describes the culture and characterisation of pterygium derived epithelial cells. Both primary and subcultured PEC demonstrated typical morphological and immunocytochemical features of epithelial cells, including expression of cytokeratins, ESA, and mucin. Although speculative, features such as vimentin expression and staining with the AE1 MoAb suggest that these cells may be derived from altered limbal basal stem cells. ${ }^{819}$ Although a direct comparative study with cultured human limbal or conjunctival cells were not performed, a recent report by Diebold et al ${ }^{13}$ demonstrated immunoreactive and histochemical staining of cytokeratins $(\mathrm{AE} 1,3,5)$, vimentin and mucin in cultured human conjunctival epithelial cells similar to those identified in PECs. The only apparent distinction between the two epithelia was the absence of keratin 13 (a marker for nonkeratinising epithelium, identified by the AE8 antibody) in PECs. This staining difference is perhaps not due to cell culture artefact, but may be due to differences in cell differentiation, since very little or no AE8 staining was observed in pterygium tissue (Fig 4D), whereas intense AE8 signal was reported in conjunctiva. ${ }^{13}$

Parallel studies of the epithelial cells of pterygia demonstrated co-localised intense staining for AE1, AE3, and AE5, together with vimentin in more basal epithelial cells. These observations strongly suggest that passaged PEC maintain differentiation equivalent to their in vivo counterparts and may provide a useful model to study the pathogenesis of pterygia.

Human conjunctival, corneal, and limbal epithelium have successfully been maintained in short term culture, ${ }^{13} 14$ although this may be dependent in part upon the presence of fibroblasts serving as feeder cells. ${ }^{15}$ While culture studies have previously been performed on pterygium tissue, these were inconclusive with respect to the cell type(s) cultured. ${ }^{20}$ To our knowledge this is the first study to characterise pterygium derived epithelial cells and establish a pure long term culture. Future studies using these cells will be aimed at determining the effects of ultraviolet irradiation on specific gene products which may participate in proliferation, angiogenesis, inflammation, and tissue degeneration, all ongoing processes in pterygium formation.

A prominent feature of pterygia is the loss of Bowman's membrane. It has been speculated that the loss of this tissue matrix is a result of destruction by the invading pterygia, ${ }^{3}$ possibly resulting from the action of matrix metalloproteinases (MMPs). A recent investigation has demonstrated increased MMP activity in pterygia compared with normal conjunctiva. ${ }^{21}$ Future studies on the profile MMPs derived from pterygium tissue and PECs may aid in determining the class of proteases responsible of the extensive matrix remodelling characteristic of this lesion.

The importance of the epithelial cell in the pathogenesis of pterygia cannot be underestimated, as previous investigators have demonstrated the presence of intraepithelial capillaries in pterygia, suggesting that these cells may be a source of potent angiogenic cytokines. ${ }^{5}$ Analysing supernatants from stimulated PEC may reveal the identity of such factors. In addition, it would be of considerable interest to culture normal human conjunctival and corneal epithelium, in order to examine potential phenotypic variations between these cell lines.

In conclusion, we have established a pure population of epithelial cells derived from human pterygia which share common morphological, functional, and phenotypic characteristics with their in vivo counterparts. Future studies using these cells may help elucidate the mechanisms of pterygium formation, as well as being useful in the evaluation of novel therapeutic agents.

1 Ratnakar KS, Goswamy V, Agarwal LP. Mast cells and pterygium. Acta Ophthalmol 1976;54:363-8.

2 Hill JC, Maske R. Pathogenesis of pterygium. Eye 1989;3:218-26.

3 Cameron ME. Histology of pterygium: an electron microscopic study. Br f Ophthalmol 1983;67:604-8.

4 Elliott R. The aetiology of pterygium. Trans Ophthalmol Soc NZ 1961;13:22-41.

5 Seifert P, Sekundo W. Capillaries in the epithelium of pterygium. Br f Ophthalmol 1998;82:77-81.

6 Coroneo MT. Pterygium as an early indicator of ultraviolet insolation: a hypothesis. Br f Ophthalmol 1993;77:734-9.

7 Duke-Elder S. Textbook of ophthalmology. St Louis: Mosby, 1954;7:570-86.

8 Dushku N, Reid TW. Immunohistochemical evidence that human pterygia originate from an invasion of vimentinexpressing altered limbal epithelial basal cells. Curr Eye Res 1994;13:473-81.

9 Tan DTH,Lim ASM, Goh H-S, et al. Abnormal expression of the p53 tumor suppressor gene in the conjunctiva of patients the p53 tumor suppressor gene in the conjunctiva of

10 Coroneo MT, Muller-Stolzenburg NW, Ho A. Peripheral light focusing by the anterior eye and the ophthalmohelioses. Ophthalmic Surg 1991;22:705-11.

11 Kwok LS, Coroneo MT. A model for pterygium formation. Cornea 1994;13:219-24.

12 Kinoshita S, Kiorpes TC, Friend J, et al. Limbal epithelium in ocular surface wound healing. Invest Ophthalmol Vis Sci 1982;23:73-80.

13 Diebold Y, Calonge M, Fernandez N, et al. Characterization of epithelial primary cultures from human conjunctiva. Graefes Arch Clin Exp Ophthalmol 1997;235:268-76.

14 Pellegrini G, Traverso CE. Franzi AT, et al. Long-term restoration of damaged corneal surfaces with autologous cultivated corneal epithelium. Lancet 1997;349:990-3.

15 Lindberg K, Brown ME, Chaves HV, et al. In vitro propagation of human ocular surface epithelial cells for transplantation. Invest Ophthalmol Vis Sci 1993;34:2672-9.

16 Kumar RK, Maronese SE, O'Grady R. Serum-free culture of mouse tracheal epithelial cells. Exp Lung Res 1997;23. 427-40

17 Di Girolamo N, Tedla N, Lloyd A, et al. Expression of matrix metalloproteinases by human plasma cells and B lymphocytes. Eur f Immunol 1998;28:1773-84.

18 Landay A, Ohlsson-Wilhelm B, Giorgi JV. Application of flow cytometry to the study of HIV infection. AIDS 1990; 4:479-97.

19 Lauweryns B, van den Oord JJ, Missotten L. The transitional zone between limbus and peripheral cornea: an immunological study. Invest Ophthalmol Vis Sci 1993;34: 1991-9.

20 Levy WJ, Levy J, Clapper WE. Pterygium tissue culture histoimmunological study. Arch Ophthalmol 1970;83:402-5.

21 Liu YP, Schultz GS, Ren XO, et al. MMP-2 and MMP-9 levels in pterygia and matched superior conjunctiva by gelatin zymography. Invest Ophthalmol Vis Sci 1998; 39(Suppl):S756 